\title{
Cardiac Amyloidosis
}

National Cancer Institute

\section{Source}

National Cancer Institute. Cardiac Amyloidosis. NCI Thesaurus. Code C153217.

The accumulation of amyloid protein in the heart. Cardiac amyloidosis is irreversible and

may lead to conductive dysfunction as well as heart failure secondary to restrictive cardiomyopathy. 